\title{
Introduction of Communicative Language Teaching in Tourism in Cuba
}

\author{
Antonio Irizar Valdés \\ Ada Chiappy Jhones
}

In the early 80 's, ideas of the communicative approach filtered through to Cuba, but in no way are these ideas widely used in language teaching in the country today.

The importance of the tourism industry to Cuba over the past few years has resulted in a careful examination of language teaching for workers in the industry. As a result of this analysis, an experimental programme based on the ideas of the communicative approach was implemented at the Centre for Studies in Tourism in Havana in September 1987. A description of this programme will be presented.
Special emphasis will be given to the difficulties encountered by teachers in a foreign language setting who had been previously used to teaching prescribed, teacher-centred, structural methods. One of the other experimental features of this programme was the incorporation of a Canadian focus into the teaching of English in tourism, in an attempt to move away from the consideration of the U.S. and Great Britain as the only sources of English language content and social context.

Attempts to extend this type of programme to all sectors of tourism will also be described.

English language teaching has a long tradition in Cuba. The language has always been taught in the country, distinguished professors like Leonardo Sorzano Jorrin in the thirties and forties have made valuable contributions to the field, and the profession has always been open to progress and development.

But the small, dependant countries like Cuba in the forties and fifties, swayed by the ideas of American structuralism and behaviourism, were not in a condition to assimilate and balance those influences adequately. In this field, as in many others, the ideas were accepted and adopted without much reasoning, just because they came from the north. More than one generation of language teachers were formed in the ideas of structuralist and behaviourist methods, and this partial view of language and language teaching was very strong at the triumph of the revolution.

In 1959, in spite of the influence that the US Government had exerted on Cuba, and also because of it, all the latent anti-Americanism that had always simmered beneath the deceptively placid surface of Cuba-US relations surged to the top in all aspects of Cuban life, and naturally, in foreign language teaching. 


\section{The Need for Change}

Immediately after the revolution, there was an attempt to create a national home-grown programme of English language teaching, based on Cuban revolutionary themes in reaction to the previous American influence. But there was a lack of authentic language resources to support this approach. We also developed a better understanding of the global importance of English for international communication. These realizations led to a search for alternative methodologies in the late sixties. Audiolingual and audiovisual methods took hold in the country, with an overriding American structuralist influence. Only in the early eighties did ideas of the communicative approach filter through to Cuba, but in no way are these ideas widely used in language teaching in the country even today.

It was in 1981 that we came to work for tourism. While teaching English to secondary school and university students and to adult workers, we had recognized some of the conditions which undermined our efforts. It was frustrating to see the contrast between our expectations and the results obtained.

Although the fundamental role of language is to enable communication, it was evident that even after long periods of study, our students were far from being able to communicate well at the end of their courses. At best, they had acquired some grammatical knowledge, which they could only demonstrate in a very restricted stimulus-response interaction, almost exclusively represented by a class drill.

And from the point of view of motivation, at the beginning of the courses there were not enough seats for our students in class, while at the end, there were not enough students for our seats.

Trying to find answers to these and many other problems, we opted for courses with content based on the specific needs of our students. We eventually designed our own programme for a short-term course, selecting a group of hotel maids as students.

In elaborating the course, communicative teaching seemed to provide answers to some of our questions. For the first time we called our programme a syllabus, made up of functions and notions instead of grammatical structures.

In this development, we were greatly aided by Prof. Adrienne Hunter, a Canadian living in Cuba, who offered Van Ek and Alexander's, Threshold Level English and Wilkin's (1976) Notional Syllabuses as resources.

After the initial course, we began an intensive period of study, reading, research and teaching. We gained access to the ideas of Widdowson, Candlin, Morrow, Brumfit and others. We attended a post-graduate course 
on the Communicative Approach by Professor Marjorie Moore, an American who teaches at the Institute of Medical Sciences, University of Havana. We developed for our Centre an updated bibliography on language teaching. We attended some conferences in our country, presenting papers about our early experiences. Step by step communicative language teaching began to take concrete form as part of our work on language teaching for INTUR, the National Institute of Tourism.

\section{A New Look}

The tourist industry is a vital part of Cuba's economy. Its growing importance has resulted in a careful examination of language teaching for workers in the industry who need to speak English to foreign visitors. As a result of this analysis, our English Language Teaching Department, at the Centre for Studies in Tourism, was given full responsibility for the teaching of English in the whole of INTUR, and an experimental communicative programme was implemented at the Centre in Havana, in September 1987. This full-time programme was part of a general intensive course on tourism, for a group of 60 students selected from among the different tourist enterprises in Cuba.

Because of the need to assign time for other subjects in the curriculum, it was not possible to obtain the 960 hours we asked for. Nevertheless, in the end we gained some 630 hours of English, many more than had ever previously been assigned to an English course.

Using Spectrum (Byrd, 1982) as the basic text for our course, classes met four days a week, six hours a day, with two different teachers for each group. As the basis for selecting students was tourism in general, and not language, we found from the very beginning that we had four very heterogeneous groups ranging from false beginners to some who had studied English in high school or language schools, as well as others who had studied other languages before.

During the first part of the course we had to group the students according to their tourism specialities. But in the second semester we decided to arrange them according to their possibilities for learning the language, ending up with two groups of average students, plus one group above and the other below. We recognize that streaming is strongly questioned in the West. Nevertheless, given the demands and limitations we faced in Cuba, it seemed the most productive course to take.

At the end, 55 out of the 60 students who began the course, (only five seats empty this time), were tested and classified according to the results by means of a four-level proficiency scale, designed and applied for the first time for this course, with the following final outcome: 


$\begin{array}{lrl}\text { students at Level 4 } & 1 & \text { (highest) } \\ \text { students at Level 3 } & 23 & \\ \text { students at Level 2 } & 21 & \\ \text { students at Level 1 } & 10 & \text { (lowest) }\end{array}$

The course was considered successful, as all of the students who participated were able, although at different levels, to use the language for communication, and that was news for language teaching in tourism.

Among the very useful experiences we obtained from the course, it is important to mention the following ${ }^{1}$ :

- Authentic communicative practice (with tourists) was introduced for the first time in our courses, and proved to be highly motivating

- It seems to be much better to group students, from the very beginning, according to their possibilities for learning the language

- 24 hours a week for English seems to be too much for our students. The 2 hours in the afternoon were not very productive

- The textbook, Spectrum, proved to be good for the students who were highly motivated, although we introduced some modifications so as to meet the students' needs

- We concluded that intensive courses like this should be organized again, without including other subjects than English

During the course, we prepared a new class observation schedule, used for observing and discussion with the teachers of more than 50 classes, enabling us to follow their improvement step by step. It was hard, but in the end we had the first students who had been taught English communicatively, and the first communicative teachers in Cuba.

\section{Changing Teachers' Outlooks}

We want now to consider some of the difficulties encountered by teachers in a foreign language setting who had been previously used to teaching prescribed "teacher-centered structural methods," and then to refer briefly to our attempts to extend this type of programme to all sectors of tourism in Cuba.

There are certain issues that seem to arise from adopting a communicative approach to the teaching of language, involving all aspects of what Corder (1973) calls "the total language teaching operation," such as syllabus design, methodology and evaluation. But there is a crucial factor in that operation-the teacher.

There are things you can change fast: e.g., textbooks, materials, equipment.

You can change the seating arrangement of the students and the organization of your courses. But you can't change the teachers. You have to 
change their attitude towards language teaching, and that can't be done easily or fast.

There is one initial problem. It is important, with any approach, for teachers to have a good command of the language they teach, but this demand is of paramount importance in communicative language teaching, where the limitations in English language become more evident than ever before. In a country where teachers are not native speakers, who have few opportunities for systematic contact with natural and authentic language, it takes time, resources and great effort to improve teachers' abilities in English.

That is quite a problem, but there are others too for teachers. It is not easy to change-when you have always been the centre of the class, and now suddenly you have to leave the stage to the student and serve as a facilitator and a resource person, as well as a teacher.

There is also the problem of errors. You have been trained all your life to detect and prevent errors on the part of your students, and you have learned several techniques for correction. Yet now, it happens that errors are seen as a natural aspect of the process of learning, and that you shouldn't discourage students from speaking by interrupting or by correcting their errors at every opportunity.

There are other problems to sort out if we seriously accept the commitment to be communicative. What, for instance, are the chances of finding authentic materials in a non-English-speaking environment? And what are the difficulties of redesigning an evaluation system to use in the course? And adapting textbooks to meet our particular needs?

It is easy to see that the list can be very long indeed. Perhaps it is helpful to take a brief look at some of the main features of the language teaching project we are trying to accomplish:

- Creation of a national Language Teaching Centre

- Development of theoretical and methodological materials

- Upgrading and training plan for the teachers

- Selection of students for courses

- Writing of a teacher's guide to Spectrum

- Creation of a newsletter

- Selection and distribution of theoretical materials on the communicative approach

- Analysis of the level of language proficiency required for the different jobs in tourism

- Creation of a centralized bank of authentic materials

- Foreign assistance

We have already started to work on the majority of these features. Some are in the process of implementation. Others, like the teacher's guide and 
the criteria for the selection of students, were elaborated and began to function from September 1988. And still others, like the upgrading and training of teachers, will be running for a long time.

Finally, we can take up the question of foreign assistance in terms of what we like to call the "Canadian Connection." One experimental feature of this project is the incorporation of a Canadian focus into the teaching of English in tourism in Cuba, in an attempt to move away from the consideration of the US and Great Britain as the only source of English language content and social context. There are many reasons for this.

First, it is from Canada mostly that we get a steady flow of tourism every year. Thousands of Canadians come to Cuba. We've got to know what their expectations are, what they think, how they live, and obviously, how they talk.

Second, Canada has developed a great amount of knowledge and expertise in foreign language teaching, which could be a tremendous support to our own efforts, as we had the opportunity to learn at the Annual Conference of the TESL Association in Ontario in 1988.

And third, we have already started to move in this direction. Following Naiman's work with us in 1987-88, we are planning to invite others for short or long terms in coming years. We are going to incorporate in our courses a Canadian text called, Take Part (Engkent and Bardy, 1986).

Moreover, as a result of this collaboration, we are beginning to learn that with wonderful writers like Margaret Atwood and Robertson Davies, Canadians are much more than "hewers of wood and drawers of water."

It has been our concern to present not a conclusive case, but just to start an inquiry. We are a long, long way from finding ultimate answers to the many difficult questions we have been asking, but we are optimistic.

As you well remember, Hamlet was doubtful and hesitating, but we are sure that it is "nobler to take arms against a sea of troubles and by opposing end them."

\section{NOTES}

'In addition, we received very strong support from Prof. Neil Naiman of Glendon College, York University in Toronto, who helped greatly in the teaching and professional development of the teachers.

\section{REFERENCES}

Berton, Pierre. (1987). Why We Act Like Canadians. Penguin Books, Canada.

Byrd, Donald R.H. (1982). Spectrum: A Communicative Course in English. New York: Prentice Hall, Regents Publishing.

Corder, S. Pit. (1973). Introduction to Applied Linguistics. Harmondsworth: Penguin. 
Engkent, Lucia Pietrusiak \& Karen P. Bardy. (1986). Take Part. Scarborough, Ontario: Prentice Hall, Canada.

Van Ek, J.A. and L.G. Alexander. (1975). Threshold Level English. Oxford: Pergamon Press.

Wilkins, David A. (1976). Notional Syllabuses. London: Oxford University Press.

\section{THE AUTHORS}

Antonio Irizar Valdés, Associate Professor at the University of Havana, is Head of Language Teaching Department at the Centre for Studies in Tourism. He has worked as teacher, methodologist and programme designer at all levels from secondary school to university.

Ada Chiappy Jhones, Associate Professor at the University of Havana, is Coordinator of English Language teachers at the Centre for Studies in Tourism. She has worked as a teacher, methodologist and programme designer at all levels, as well as television teaching. 